\title{
Research on Cultivating Top Students in Flipped College English Classroom
}

\author{
Xixiang Ke \\ Wuhan Textile University, Wuhan, China 430070 \\ 1753270552@qq.com
}

\section{Keywords: Flipped classroom; Top students; College English; Autonomous learning}

\begin{abstract}
Much attention is focused on the study of flipped classroom. This research is conducted among top students with the purpose of confirming the effect of flipped classroom. It found that flipped classroom does not merely implies learning by oneself, even if objects are top students, teachers are expected to engage more frequently in the learning process than they do in the conventional class. Teachers should develop students' autonomous learning and design pre-class and while-class activities carefully to develop a higher level of cognitive skills such as applying, creating, analyzing and evaluating. It is concluded that top students can reap a lot from flipped classroom with interest and efficiency improved, yet still under the monitor of teachers. Some reflections are offered afterwards.
\end{abstract}

\section{Introduction}

There is a trend for higher education institutions to conduct flipped classrooms which shift teaching focus from traditional and passive cramming lecturing to an active participation of students and teachers. Education aims to satisfy the need of students. Not only are homework and lecture flipped, but students are also flipped to be the center of learning process.

\section{Research at Home and Abroad}

Research on flipped classroom roughly involves such fields as engineering, agriculture, math, economy etc. Researchers elaborate flipped classroom from the perspective of teaching methods, teaching strategies and empirical studies. Flipped classroom began to capture the attention at home in 2012, then became the focus in 2013. The relevant research covers such aspects as the feasibility of implementing flipped classroom teaching in China(Bu Caili, 2016)[1], teaching pattern and teaching methods(Bishop, J. \& M. Verleger, 2013)[2], and the instruction to teaching cases(Hu Jiehui, Wu Zhongjie, 2014)[3]. To conclude, more are on middle school or primary teaching and less on college teaching. This study aims to explore teaching effect of flipped classroom among top students with positive elements of traditional teaching combined.

The significance and benefits of implementing flipped classroom are as follows.

It helps to improve the quality of teaching. Teaching the knowledge ahead of time in flipped classroom allows students more time to complete the internalization of knowledge in class. Students can carry out personalized learning according to their own needs, learning being more relaxing. In classroom activities, students can explore learning problems with the help of teachers and students so that learning becomes efficient.

It is conducive to promoting the comprehensive development of college students. Flipped classroom subverts traditional classroom teaching pattern, students changing from passive learning into active learning, classroom learning into extracurricular learning. There are free choices for learning time, place, content, ways and methods. These will accelerate the development of students' self-control, self-learning, cooperation, coordination, information technology operation ability and finally improve comprehensive ability of English application.

It is beneficial to promote professional development of teachers in colleges and universities. Flipped classroom brings new challenges to teachers. In order to meet the needs of flipped classroom teaching, teachers should be capable of designing, directing and acting for teaching. 
Media production and information technology capabilities are necessary for teachers. With the increase of depth and breadth of knowledge, flipped classroom has profound impact on the development of teachers.

\section{Method}

Research objects are from Class A- Top students in Wuhan Textile University. In this research, we adopt the method of descriptive analysis and attempts to confirm the effect of the teaching mode based on flipped classroom and the role of the teacher in the flipped classroom with traditional teaching integrated. It aims to explore flipped classroom teaching effect and mode with effective elements of traditional teaching. The research lasts a semester, and a pre-test and post-test are conducted. Interview of students and teachers are conducted, either.

Implementation of Research -the Tasks and Activities in the Flipped Classroom. Based on Hwang (2015)[4] seamless flipped learning model, the tasks and activities in flipped classroom are presented below.

Question Exploration. In this stage, teachers select questions related to learning content and have students discuss and put forward relevant questions. The task is to sort out language points or language culture thus conduct the research of social phenomena which has something to do with language. Students at this stage explore target questions. The language can be a research object itself, or as a tool, or as a resource.

Peer Competition. Moderate competition in education is beneficial because it can promote learner self- management. Games or contests can be stimulus to facilitate the occurrence of learning from the aspects of practice and interest.

Knowledge Construction Tools. Knowledge construction tools help learners to organize knowledge and cultivate critical thinking ability (Jonassen, 1996[5]; Jonassen et al., 1998[6]). Learning activities with knowledge construction allow learners to review existing knowledge and design effective learning which can merge existing knowledge into new knowledge. For example, concept map is a typical knowledge construction tool with which we can draw a map displaying various concepts that can act as visual tools for students to organize knowledge.

Task-based Individual Learning. In the flipped mode, task design is student-centered. Students can choose to finish tasks in groups or by themselves. As students finish thinking and resource collection before class in a relatively independent environment, the way they present, explain and deal with problems may differ from those in traditional class, thus teachers should be capable of summarizing students' explanations and link them to the focus of teaching objective.

Learning Based on Problems. It is natural for teachers to have students associate the existing knowledge with new knowledge together and complement each other. The final purpose of student discussion may be to solve the problems, but perhaps more attention is paid to the way or means students adopt in the process of solving problems and to observe how they define problems in a specific context and analyze events, seek solutions, and finally make decisions.

Peer Evaluation. Peer evaluation, will improve learner's learning efficiency and reflect the quality of task, which also allows them to assess their own evaluation Quasi. Teachers are supposed to clearly state evaluation standard in the task design, which is both the standard of the evaluation in the preparation process and that of peer assessment.

Project- based Collaborative Learning and Knowledge Sharing. Different from individual learning above, collaborative learning focuses on team cooperation and division of labor. For different majors, teachers can take into account interdisciplinary subjects or topics, thus can have them develop expertise and attain new information from different fields. If learners can maintain a sense of freshness and curiosity about the application of language, positive participation in pre-class preparation and good classroom presentation are expected. 


\section{Discussion and Results}

In general, student post-test results indicate they have performed better than before, but not make significant progress. Interviews show most students are more interested in the learning and participate more frequently in the class. A few students are strained thus feel bored in class.

For some students' stress, teachers can reform teaching strategy. Flipped classroom can be applied to one teaching period, or several teaching periods focusing on particular units or knowledge, not to the whole semester for all the content. This may relieve students' nervousness in class. Besides, having students as teachers explain learning content is a choice. It depends on how hard learning content is. This strategy can be employed flexibly according to the difficulty index of content.

Reflections on the Role of Teachers. Flipped classroom is demanding for teachers. Teaching content transmission and autonomous learning effect are to be ensured. Tasks and activities design are challenges to teachers. If students can learn effectively under the guidance of teachers, learning communities are expected to be formed. The role of teachers changes much.

First, introduction to flipped classroom is necessary for students. As students' guide, assistant and facilitator, teachers' concept of learning can have a very positive impact on their formation of learning ideas. If students agree with the teacher's teaching concept, they will actively cooperate with the teachers, combining autonomous learning with class learning.

Second, tasks should be a little tougher than learner's existing level according to Krashen's "i+1" theory. The depth, the level and the concrete structure of learning are all related to the effect of learning. Teachers who are armed with the knowledge of subjects concerned and of the mutual relationship among important points need to grasp the "knowledge map" of the subject, teaching content and teaching objective and classify learning elements. Equipped with knowledge, teachers should be capable of designing ways to present teaching content so that students can identify important points.

Response to students' learning needs is anticipated. In flipped classroom, students' needs and expectations are a bit different from those of traditional one. Teachers should have psychological expectations and make an effective response. Teachers should be aware of what students generally lack and what students fail to grasp. Adjusting the pace of teaching according to students' learning conditions is indispensable. Teachers design various tasks with different difficulty index based on students' level and teaching objective and balance language points and knowledge points. The discussion should be focused on broadening horizon and cultivating critical thinking via topics familiar to students. Emphasis can be placed on analyzing new knowledge.

Besides, the completion of pre-class task acts as the basis of classroom teaching. The problems which emerge in the pre-class tasks are the focus of class interaction, thus the whole in-class teaching process goes on in cooperation and discussion. Teaching plan by teachers that can inspire students' motive is indispensable (Kim, K., M. Kim, O. Khera \& J. Getman, 2014)[7]. Students' critical thinking is to be cultivated thus they actively participate in subsequent discussion. Homework feedback should be given as soon as possible. Teachers' comments which cover merits and demerits of homework will contribute to students' self improvement. As a result, students will expect to obtain teachers' feedback.

Creating opportunities for students to interact something concerning learning strategies, which is of significance for cultivating autonomous learning ability. Putting students with different characteristics into one group helps them to learn each other. Teachers as organizers, observers and participant can get to know each student's merit and demerits. The differences among students are a good platform for them to complement each other.

Adding pleasure to class teaching is essential. Tasks that can stimulate their interest are assigned. Having students engage in teaching will have positive impact on teaching. One hand, students come up with many good ideas by collecting various information; on the other hand, they can exercise their ability to express and increase their confidence via active participation. For example, students can be assigned the task of writing a report on the topic they debate. 
Teaching students how to learn is beneficial. Teacher's guidance helps to activate the learner's relevant ability, thus lead them to complete learning and output. Teachers must be ready for observing students' discussion, giving feedback on their problems in a timely manner and evaluating learning process. Before task assigning, necessary materials can be provided for learners to construct appropriate cognitive models, encouraging them to weigh and make plans and innovations.

It is indispensable to update knowledge reserve. One of the aims of education is to lead students to success, for the classroom in 2020 and in 2010 should be different. Information and knowledge updating is essential for education scholars, managers or teachers. This contains many levels, which can be daily network terminology(Prunuske, A.J., J. Batzli, E. Howell, \& S. Miller, 2012)[9], something related to student's living environment; it can also be groping for micro lessons and showing content in a way that has not been previously employed. Teachers can also share with students the latest dynamic research of this subject. In addition, teaching and research develop simultaneously, thus teaching reform is sustainable.

Reflection on the Role of Students. Students' autonomous learning ability is required in the flipped classroom. Without autonomous learning of students, flipped class can't go on smoothly and achieve its learning objectives (Ma Xiulin, Zhao Guoqing, Wutong, 2013[8]; Snowden, K. E 2012[10]). Students are no longer passive learners, but active explorers. Students can challenge peers and teachers by putting forward questions and discussing with teachers and peers. They can be negotiators and negotiate with teachers everything about subjects. They are equal to teachers and have a fruitful relationship with teachers. Students are closer to teachers and tend to convey their own ideas with teachers. Under such circumstances, learning effect is strengthened. Students design learning content and pace with the help of teachers. With the time going on, teachers gradually have students plan learning independently without teachers' instruction. They can be designers, creators and inventors. Their potential can be given full play. They understand their own preferences and interests and needs. Therefore, situations created by them are to their taste.

\section{Conclusion}

Flipped classroom is not the same as the student's complete self-study, thus teacher's guidance is very vital and students' participation is more than traditional class. Because teachers' design, organization and their own speculative ability in this process will guide the direction of the learners. Teachers' design has impact on whether learners can really put heart into discussion and benefit from teachers. Self management awareness of learners, learning motivation and autonomous ability are key factors affecting the effectiveness of learning. Emphasis can be put on strategy design to motivate students.

It is true that flipped classroom can't be used to solve all the teaching problems concerned. Flipped classroom is sure to experience the "localization" of the process since it is originated from the United States. It may not apply to all disciplines, nor is it suitable for all the teachers or students, but at least it creates a different classroom atmosphere and provides a pattern of student-centered teaching and learning.

\section{Acknowledgement}

My gratitude goes to education department of Hubei Province for its financial support and to Professor Xiang Rong for her help with data collection and eventual completion of the paper. This paper is one of researches of 2016 Teaching and Research Project for education department of Hubei Province.

\section{References}

[1] Bu Caili, Reflections on Flipped Classroom Study at Home Distance Education 2016(2):26-33. (In Chinese) 
[2] Bishop, J. \& M. Verleger. The flipped classroom: A survey of the research. Paper presented at the 120th ASEE Annual Conference \& Exposition, Atlanta, GA, 2013.

[3] Hu Jiehui, Wu Zhongjie. Research on the College English Teaching Model Based on MOOC. Technology Enhanced Foreign Language Education, 2014,11: 40-45.(In Chinese)

[4] H wang, J., L. Lai \& Y. Wang. Seamless flipped learning: A mobile technology-enhanced flipped classroom with effective learning strategies. J. Comput Educ, 2015(2)4:449-473. (Springer, doi: 10.1007/s40692-015-0043-0).

[5] Jonassen, H. Computers in the Classroom: Mindtools for Critical Thinking. Cloumbus OH:Merrill/Prentice-Hall, 1996.

[6] Jonassen, H., C. Carr \& P. Yueh. Computers as Mindtools for engaging learners in critical thinking. TechTrends, 1998(43)2:24-32.

[7] K im, K., M. Kim, O. Khera \& J. Getman. The experience of three flipped classrooms in an urban university: An exploration of design principles. Internet and Higher Education, 2014(22):37-50.

[8] Ma Xiulin, Zhao Guoqing, Wutong. An Empirical Study on IT Flipped Classroom. Distance Education, 2013(1): 79-85. (In Chinese)

[9] Prunuske, A.J., J. Batzli, E. Howell, \& S. Miller. Using online lectures to make time for active learning. Genetics Education, 2012, 192(1): 67-72.

[10] Snowden, K. E. Teacher Perceptions of the Flipped Classroom: Using Video Lectures Online to Replace Traditional In-class Lectures. University of North Texas, 2012. 